\title{
From tumor regression to molecular diagnostics-modern lung pathology
}

\author{
Klaus Junker \\ Institute of Pathology, Klinikum Bremen-Mitte, D-28177 Bremen, Germany \\ Correspondence to: Klaus Junker. Institute of Pathology, Klinikum Bremen-Mitte, St.-Juergen-Strasse 1, D-28177 Bremen, Germany. \\ Email: klaus.junker@klinikum-bremen-mitte.de.
}

Received: 29 December 2019; Accepted: 18 February 2020; Published: 25 August 2020.

doi: $10.21037 /$ ccts.2020.02.08

View this article at: http://dx.doi.org/10.21037/ccts.2020.02.08

\section{Tumor regression}

Lung cancer continues to be the most common tumorrelated cause of death. Within the scope of neoadjuvant therapy concepts for non-small cell lung cancer (NSCLC), the following grading of therapy-induced tumor regression was established over 20 years ago:

* RG I: no or only spontaneous tumor regression in the tumor bed of the primary tumor and in the regional lymph nodes.

* RG II: morphological evidence of therapy-induced tumor regression with:

- RG IIa: more than $10 \%$ of viable tumor cells in the tumor bed of the primary tumor and/ or regional lymph nodes presenting more than focal microscopic disease;

- RG IIb: maximum of $10 \%$ of viable tumor cells in the tumor bed of the primary tumor and/ or regional lymph nodes presenting only focal microscopic disease.

* RG III: complete tumor regression without evidence of viable tumor in the tumor bed of the primary tumor and in the regional lymph nodes.

Applying this regression grading, a statistically significant longer median survival time could be demonstrated for patients with stage III NSCLC and a maximum of $10 \%$ of viable tumor tissue in the resection specimens after neoadjuvant therapy (regression grade IIb/III) than for patients with tumors of regression grade I or IIa. In a corresponding trial, the extent of tumor regression (regression grade I/IIa versus regression grade IIb/III) could be established as an independent prognostic factor for patients treated with tumor resection (1-5).
Recently, the International Association for the Study of Lung Cancer (IASLC) has also developed multidisciplinary recommendations for pathologic assessment of lung cancer resection specimens following neoadjuvant therapy. In these recommendations, major pathologic response (MPR) is defined as the reduction of viable tumor to the amount beneath an established clinically significant cutoff based on prior evidence according to the individual histologic type of lung cancer and a specific therapy. The historical definition of MPR for all histologic types of lung cancer is $\leq 10 \%$ of viable tumor with no viable tumor required for complete pathologic response (CPR) (6). The definitions of MPR and CPR therefore largely match those of regression grades IIb and III, respectively.

\section{Histologic typing}

The histologic typing of lung tumors is based on the WHO classification of tumors of the lung, pleura, thymus and heart (7), currently in its 4th edition. In order to meet the requirements of current treatment options, it is necessary to perform the most precise histologic typing of NSCLC, even on (small) biopsies and cytological specimens. Typing as "NSCLC-NOS" (non-small cell lung cancer-not otherwise specified) should be avoided as far as possible by using complementary histochemical and immunohistochemical examinations $(7,8)$.

According to the $\mathrm{WHO}$ classification, immunohistochemical confirmation of neuroendocrine differentiation is mandatory only for the diagnosis of large cell neuroendocrine carcinoma (7). Moreover, corresponding investigations as well as the immunohistochemical determination of the Ki67 proliferation index are recommended for all neuroendocrine 


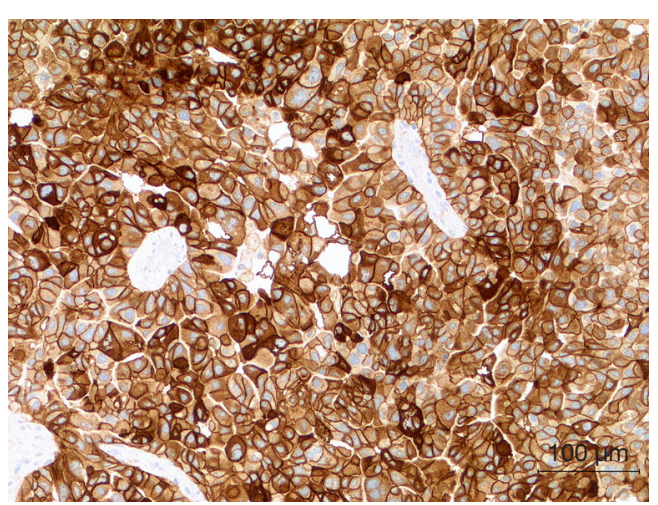

Figure 1 PD-L1 immunohistochemistry, E1L3N antibody (Cell Signaling Technology, Danvers, MA, USA), TPS (Tumor Proportion Score): 100\%, pulmonary adenocarcinoma, 58 years old female. PD-L1, programmed cell death-ligand 1.

lung tumors in order to reliably avoid differential diagnostic problems, e.g., in differentiating between small cell carcinoma versus lymphoma or artificially altered infiltrates of a typical carcinoid versus small cell carcinoma $(8,9)$.

\section{Molecular diagnostics}

Since the first Epidermal growth factor receptor (EGFR) tyrosine kinase inhibitor for the treatment of EGFRmutated pulmonary adenocarcinomas was approved in the $\mathrm{EU}$ in 2005 , an increasing number of new drugs have been introduced, the application of which requires the performance of molecular diagnostics.

According to the current German S3 Guideline $(8,9)$ and the ESMO Guidelines (10), molecular pathological investigations concerning EGFR (exons 18-21) and BRAF V600 mutations as well as Anaplastic lymphoma kinase (ALK) and ROS1 fusions are to be carried out for all noncuratively treatable non-squamous NSCLC and squamous cell carcinomas of never smokers or light smokers. In parallel to the molecular investigations, the extent of PDL1 expression in all stage IV NSCLC should be tested and reported as tumor proportion score (TPS) (9). Due to a recent approval, the analysis of an neurotrophic tyrosine receptor kinase (NTRK) 1-3 translocation gains additional importance.

\section{EGFR}

EGFR represents a receptor tyrosine kinase whose dimerization leads to the activation of a signal transduction cascade with consecutively increased cell proliferation and angiogenesis as well as reduced apoptosis. In Europe, EGFR mutations are detected in $10-15 \%$ of non-squamous NSCLC, most often as a deletion in exon 19 or a point mutation in exon 21. A T790M mutation in exon 20 is the most common mechanism of resistance in the course of therapy with first or second generation EGFR TKIs (11).

\section{BRAF}

The BRAF protein is a component of the MAP kinase signaling pathway. Mutations of the corresponding genemost frequently V600E mutations-are described in up to $3 \%$ of NSCLC and cause an over-activation of this signaling pathway. In addition to a target for molecular therapy, BRAF mutations also include a mechanism of EGFR-TKI resistance.

\section{ALK}

ALK translocations are also described in up to $3 \%$ of NSCLC. The most common is an EML4 (echinoderm microtubule-associated protein-like 4)-ALK fusion with formation of a new EML4-ALK gene (11).

\section{ROS1}

The ROS1 receptor-tyrosine-kinase is encoded by the corresponding proto-oncogene. ROS1 gene rearrangements, which are detected in about $1 \%$ of NSCLC, promote their carcinogenesis by a not yet fully understood mechanism. CD74 is the most common ROS1 fusion partner (12).

\section{PD-L1}

Under physiologic conditions, PD-L1 (programmed cell death-ligand 1) is important for maintaining the homeostasis of the immune system in the healthy organism. But PD-L1 is also expressed on tumor cells of NSCLC with the aim to escape the immune system. Therapeutically, the physiologic immune response is reconstituted by means of anti-PD-1 or anti-PD-L1-antibodies (13). The extent of the PD-L1 expression is investigated by immunohistochemistry and reported as a tumor proportion score (TPS) (Figure 1).

\section{NTRK 1-3}

The genes NTRK 1-3 encode three tropomyosin receptor 
kinase proteins (TRKA, TRKB, TRKC). In about one percent of all solid malignancies, there is a NTRK fusion with expression of a chimeric protein, itself followed by a constitutively active, ligand-independent downstream signaling (14).

In September 2019, a TRK inhibitor was approved by the EMA (European Medicines Agency) for the treatment of locally advanced or metastatic solid tumors with NTRK gene fusion. This therapy is therefore also available for corresponding lung cancers.

In addition to the molecular changes described above, especially in the case of resistance to therapy, supplementary molecular investigations can be carried out with an expanded panel in order to offer the respective patients the possibility of therapy with drugs not approved for lung cancer or the participation in a therapy trial.

In summary, modern lung pathology increasingly requires molecular examinations with regard to specific therapy options in addition to exact histologic typing according to the WHO classification. In the context of neoadjuvant therapy concepts, the extent of therapyinduced tumor regression gains additional importance.

\section{Acknowledgments}

Funding: None.

\section{Footnote}

Provenance and Peer Review: This article was commissioned by the Guest Editors (Francesco Zaraca, Reinhold Perkmann, Luca Bertolaccini and Roberto Crisci) for the special series "Thoracic Surgery Without Borders" published in Current Challenges in Thoracic Surgery. The article did not undergo external peer review.

Conflicts of Interest: The author has completed the ICMJE uniform disclosure form (available at https://ccts.amegroups. com/article/view/10.21037/ccts.2020.02.08/coif). The special series "Thoracic Surgery Without Borders" was commissioned by the editorial office without any funding or sponsorship. The author has no other conflicts of interest to declare.

Ethical Statement: The author is accountable for all aspects of the work in ensuring that questions related to the accuracy or integrity of any part of the work are appropriately investigated and resolved.
Open Access Statement: This is an Open Access article distributed in accordance with the Creative Commons Attribution-NonCommercial-NoDerivs 4.0 International License (CC BY-NC-ND 4.0), which permits the noncommercial replication and distribution of the article with the strict proviso that no changes or edits are made and the original work is properly cited (including links to both the formal publication through the relevant DOI and the license). See: https://creativecommons.org/licenses/by-nc-nd/4.0/.

\section{References}

1. Junker K. Therapy-induced tumor regression and regression grading in lung cancer. Pathologe 2014;35:574-7.

2. Thomas M, Ruebe C, Semik M, et al. Impact of preoperative bimodality induction including twice-daily radiation on tumor regression and survival in stage III non-small-cell lung cancer. J Clin Oncol 1999;17:1185-93.

3. Junker K, Langner K, Klinke F, et al. Grading of tumor regression in non-small cell lung cancer: Morphology and prognosis. Chest 2001;120:1584-91.

4. Junker K. Histopathologic evaluation of mediastinal lymph nodes in lung cancer. Lung Cancer 2004;45:S79-S83.

5. Junker K, Stachetzki U, Rademacher D, et al. HER2/neu expression and amplification in non-small cell lung cancer prior to and after neoadjuvant therapy. Lung Cancer 2005;48:59-67.

6. Travis WD, Dacic S, Wistuba I, et al. IASLC multidisciplinary recommendations for pathologic assessment of lung cancer resections specimens following neoadjuvant therapy. J Thorac Oncol 2020. In press.

7. Travis WD, Brambilla E. Burke AP, et al. WHO classification of tumours of the lung, pleura, thymus and heart. 4th ed., IARC, Lyon. 2015.

8. Junker K, Büttner R, Langer T, et al. Pathologicalanatomocal diagnosis according to the German lung cancer guideline 2018. Pathologe 2018;39:589-603.

9. Leitlinienprogramm Onkologie (Deutsche Krebsgesellschaft, Deutsche Krebshilfe, AWMF) (2018) Prävention, Diagnostik, Therapie und Nachsorge des Lungenkarzinoms, Langversion 1.0, AWMF-Registernummer 020/007OL. Available online: http://leitlinienprogramm-onkologie.de/ Lungenkarzinom.98.0.html

10. Planchard D, Popat S, Kerr K, et al. Metastatic NonSmall-Cell Lung Cancer: ESMO Clinical Practice Guidelines for diagnosis, treatment and follow-up. Ann Oncol 2018;29:iv192-237. 
11. Dong J, Li B, Lin D, et al. Advances in targeted therapy and immunotherapy for non-small cell lung cancer based on accurate molecular typing. Front Pharmacol 2019;10:230.

12. Gkolfinopoulos S, Montzios G. Beyond EGFR and ALK: targeting rare mutations in advanced non-small cell lung cancer. Ann Transl Med 2018;6:142.

doi: $10.21037 /$ ccts.2020.02.08

Cite this article as: Junker K. From tumor regression to molecular diagnostics-modern lung pathology. Curr Chall Thorac Surg 2020;2:32.
13. Scheel AH, Dietel M, Heukamp LC, et al. Harmonized PD-L1 immunohistochemistry for pulmonary squamouscell and adenocarcinomas. Mod Pathol 2016;29:1165-72.

14. Drilon A, Laetsch TW, Kummar S, et al. Efficacy of Larotrectinib in TRK fusion positive cancers in adults and children. N Engl J Med 2018;378:731-7. 